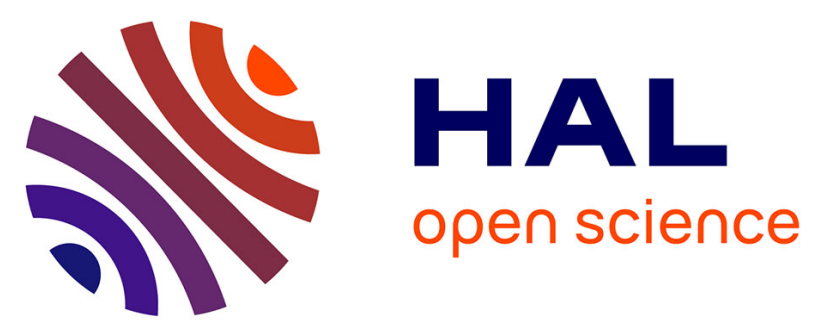

\title{
First-Principles Study on the Effect of Pure and Oxidized Transition-Metal Buffers on Adhesion at the Alumina/Zinc Interface
}

Ha-Linh Thi Le, Jacek Goniakowski, Claudine Noguera, Alexey Koltsov, Jean-Michel Mataigne

\section{To cite this version:}

Ha-Linh Thi Le, Jacek Goniakowski, Claudine Noguera, Alexey Koltsov, Jean-Michel Mataigne. First-Principles Study on the Effect of Pure and Oxidized Transition-Metal Buffers on Adhesion at the Alumina/Zinc Interface. Journal of Physical Chemistry C, 2016, 120 (18), pp.9836-9844. 10.1021/acs.jpcc.6b02182 . hal-01323342

\section{HAL Id: hal-01323342 \\ https://hal.science/hal-01323342}

Submitted on 7 Jul 2020

HAL is a multi-disciplinary open access archive for the deposit and dissemination of scientific research documents, whether they are published or not. The documents may come from teaching and research institutions in France or abroad, or from public or private research centers.
L'archive ouverte pluridisciplinaire HAL, est destinée au dépôt et à la diffusion de documents scientifiques de niveau recherche, publiés ou non, émanant des établissements d'enseignement et de recherche français ou étrangers, des laboratoires publics ou privés. 


\section{First Principles Study on the Effect of Pure and}

\section{Oxidized Transition Metal Buffers on Adhesion at the Alumina/Zinc Interface.}

Ha-Linh Thi Le, ${ }^{\dagger, \ddagger}$ Jacek Goniakowski, ${ }^{*, \dagger, \ddagger}$ Claudine Noguera, ${ }^{\dagger, \ddagger}$ Alexey Koltsov, and Jean-Michel Mataigne

CNRS, UMR 7588, Institut des Nanosciences de Paris, F-75005 Paris, France, Sorbonne

Universités, UPMC Univ Paris 06, UMR 7588, INSP, F-75005 Paris, France, and

ArcelorMittal Maizières Research, voie Romaine, F-57280, Maizières lès Metz, France

E-mail: Jacek.Goniakowski@insp.jussieu.fr

Phone: +33 (0)1 442746 17. Fax: +33 (0)1 44273982

${ }^{*}$ To whom correspondence should be addressed

${ }^{\dagger}$ CNRS, UMR 7588, Institut des Nanosciences de Paris, F-75005 Paris, France

${ }^{\ddagger}$ Sorbonne Universités, UPMC Univ Paris 06, UMR 7588, INSP, F-75005 Paris, France

`ArcelorMittal Maizières Research, voie Romaine, F-57280, Maizières lès Metz, France 


\begin{abstract}
In view of improving the performance of anti-corrosive zinc coatings, we report a first principles DFT study on the effect of a metal buffer on the adhesion characteristics at the weakly interacting alumina/zinc interface. With results obtained for metals across the first transition series $(\mathrm{M}=\mathrm{Cr}, \mathrm{Fe}, \mathrm{Ni})$ we show that such buffers may enhance considerably the interface strength, the effect being particularly well pronounced for Cr. Moreover, relying on a series of model $\mathrm{MO}_{x}$ oxide buffers $(\mathrm{x}=1,3 / 2,2)$, we demonstrate that buffer oxidation is in most cases detrimental to adhesion. Systematic analysis of the interfacial bonds enables to ascribe the predicted beneficial effect of metallic buffers to the formation of strong interfacial metal-oxygen and metal-zinc bonds. Reduction of the number of such bonds upon buffer oxidation drives the decrease of interface adhesion. If the oxidation of buffers composed of more reactive metals cannot be avoided, late transition elements may be more promising candidates for practical applications.
\end{abstract}

\title{
1 Introduction
}

Metal-oxide interfaces have been intensively studied because of their commercial and scientific importance, with applications that range from microelectronics, to engineering of thermal coatings, or formation of protective scales. Many fundamental studies have been dedicated to the question of adhesion strength of transition and noble metals on oxide surfaces. ${ }^{1-5}$ Such questions arise nowadays also in the context of optimization of galvanic zinc coatings, which have long-proved their efficiency as anti-corrosive protection of steels. ${ }^{6}$ Routinely, before applying the zinc coating, cold-rolled steel strips undergo a recrystallisation annealing at about $800^{\circ} \mathrm{C}$ in a reducing $\mathrm{N}_{2}-5 \% \mathrm{H}_{2}$ atmosphere to remove stresses and residual iron oxides. ${ }^{6-9}$ Since the novel, advanced high strength steels (AHSS) are purposely enriched in strengthening elements, such as $\mathrm{Al}, \mathrm{Si}$ and $\mathrm{Mn},{ }^{10-14}$ the annealing results in a selective oxidation of the electropositive alloyed elements. Oxide segregation at the steel surface re- 
duces dramatically the adhesion of the anti-corrosive Zn protection. ${ }^{6,9}$ Typically, a $1.5-8$ wt. \% enrichment of steel with aluminum, may lead to the formation of a quasi-continuous alumina film at the surface, which efficiently impedes zinc adhesion in the standard hot-dip galvanization process. Indeed, the galvanization switches from what is close to a reactive interface with a bare iron surface ${ }^{6,15}$ to a non-reactive interface with wide band-gap oxides such as alumina.

In the present study we focus on the $\alpha-\mathrm{Al}_{2} \mathrm{O}_{3}(0001)$ surface, which displays surface characteristics similar to those of more complex $\gamma$-alumina crystallites identified in model steel oxidation experiments ${ }^{16}$ or to those observed on industrial grades. ${ }^{9}$ The Al-terminated, non polar, stoichiometric basal (0001) plane ${ }^{17,18}$ the most stable surface in vacuum environment,${ }^{19}$ is a reference for the studies of metal-oxide interfaces. ${ }^{1,20-24}$ Despite a strong applicative interest and the widespread use of sapphire in the growth of epitaxial zinc oxide layers ${ }^{25}$ the nature of interactions and the adhesion strength at alumina/zinc interface have received only little attention in the past. ${ }^{26-29}$ In a previous theoretical study we have shown that zinc adatoms interact weakly with the most stable, stoichiometric $\alpha-\mathrm{Al}_{2} \mathrm{O}_{3}(0001)$ surface, which is consistent with the poor wetting of anti-corrosive coatings. ${ }^{28}$ An increase of bonding strength can only be induced by a net surface charge due to either surface polarity or to an excess of surface hydroxyls. Alternatively, since transition metals, such as $\mathrm{Cr}$, interact with the alumina surface much more strongly, ${ }^{1,29}$ we have argued that a metallic buffer at the interface may produce a strong adhesion, similar to that obtained by metal deposition at polar oxygen-rich alumina termination. ${ }^{29}$

The goal of the present study is to investigate in a systematic way the impact of such metallic buffers on $\mathrm{Zn}$ adhesion at the stoichiometric $\mathrm{Al}_{2} \mathrm{O}_{3}$ surface. To this end we consider buffers of metals across the second half of the first transition series, focusing on elements routinely used in the production of stainless steels $(\mathrm{M}=\mathrm{Cr}, \mathrm{Fe}$, and $\mathrm{Ni})$. Moreover, as to systematically account for the effect of buffer oxidation and different oxygen content in the buffer layer, we also examine interface adhesion with a series of model $\mathrm{MO}_{x}$ buffers $(\mathrm{x}=1$, 
$3 / 2,2)$. With the help of a detailed bond analysis we are able to link the interface energetics at both $\mathrm{Al}_{2} \mathrm{O}_{3} / \mathrm{MO}_{x}$ and $\mathrm{MO}_{x} / \mathrm{Zn}$ interfaces to the strength and the number of interfacial $\mathrm{M}-\mathrm{O}$ and M-Zn bonds, respectively.

The paper is organized as follows. After presenting the details and settings of the computational approach in Sec. 2, we report the results on interfaces with purely metallic (Sec. 3) and with oxidized (Sec. 4) buffers and the corresponding interfacial bond analysis. A discussion of the possibility of adhesion improvement of $\mathrm{Zn}$ on alumina by transition metal buffers in different oxygen environments is given in Sec. 5.

\section{Computational details}

All calculations are performed within the Density Functional Theory (DFT), implemented in VASP (Vienna ab initio simulation package). ${ }^{30,31}$ The interaction of valence electrons with ionic cores is described within the projector augmented wave (PAW) method, ${ }^{32,33}$ and the Kohn-Sham orbitals are developed on a plane-wave basis set with a cutoff energy of 400 eV. All calculations are spin-polarized and the relative stability of simple non-magnetic, ferro- and antiferro-magnetic solutions is systematically tested. The dispersion-corrected GGA (optB88-vdW) ${ }^{34-36}$ exchange-correlation functional is used to improve the description of adhesion characteristics, especially at weakly interacting metal/alumina interfaces, such as between $\mathrm{Zn}$ and the stoichiometric alumina(0001) termination. ${ }^{28}$ Since it has a relatively small effect on the energetic trends, we do not employ the GGA+U approach to correct the electronic structure of some of the considered transition metal oxides. ${ }^{29}$ The above settings assure a satisfactory agreement between calculated and experimental characteristics of bulk $\mathrm{Al}_{2} \mathrm{O}_{3}, \mathrm{ZnO}, \mathrm{Zn}$, and the considered transition metals, Tab. 1.

In all calculations, we use the $(1 \times 1)-\mathrm{Al}_{2} \mathrm{O}_{3}(0001) / /(\sqrt{3} \times \sqrt{3}) \mathrm{R} 30^{\circ}-\mathrm{Zn}(0001)$ coincidence cell, which provides a particularly small mismatch between the two lattices $(\leq 3 \%)$ and produces numerically tractable supercells. Superlattices used to model various interfaces 
Table 1: Calculated and experimental characteristics of bulk materials: lattice parameters $a$ and $c(\AA)$, nearest neighbor distance $d(\AA)$, and formation energy $\mathrm{E}_{\text {form }}\left(\mathrm{eV} /\right.$ formula unit). In the case of metals $(\mathrm{Zn}, \mathrm{Cr}, \mathrm{Fe}$, and $\mathrm{Ni}) \mathrm{E}_{\text {form }}$ is given with respect to isolated metal atoms. In the case of oxides $\left(\mathrm{Al}_{2} \mathrm{O}_{3}, \mathrm{ZnO}\right) \mathbf{E}_{\text {form }}$ is referred to the corresponding bulk metal and free $\mathrm{O}_{2}$ molecules.

\begin{tabular}{lllcc} 
& $\mathrm{a}(\AA)$ & $\mathrm{c}(\AA)$ & $\mathrm{d}(\AA)$ & $\mathrm{E}_{\text {form }}(\mathrm{eV})$ \\
\hline $\mathrm{Al}_{2} \mathrm{O}_{3}$ & & & & \\
GGA-vdW & 4.81 & 13.11 & $1.87 / 1.99$ & 17.03 \\
Exp. & $4.76^{37}$ & $12.99^{37}$ & $1.85 / 1.97$ & 17.43 \\
\hline $\mathrm{ZnO}$ & & & & \\
$\mathrm{GGA}-\mathrm{vdW}$ & 3.27 & 5.30 & 1.99 & 3.34 \\
Exp. & $3.25^{38}$ & $5.21^{38}$ & 1.95 & 3.64 \\
\hline $\mathrm{Zn}$ & & & & \\
GGA-vdW & 2.66 & 4.99 & $2.66 / 2.93$ & 1.07 \\
Exp. & $2.66^{38}$ & $4.95^{38}$ & $2.66 / 2.91$ & $1.35^{39}$ \\
\hline $\mathrm{Cr}$ & & & & \\
GGA-vdW & 2.84 & & 2.46 & 4.16 \\
Exp. & $2.88^{40}$ & - & 2.50 & $4.10^{39}$ \\
\hline Fe & & & & \\
GGA-vdW & 2.83 & & 2.45 & 5.04 \\
Exp. & $2.84^{40}$ & - & 2.46 & $4.28^{39}$ \\
\hline Ni & & & \\
GGA-vdW & 3.52 & & 2.49 & 4.97 \\
Exp. & $3.53^{40}$ & - & 2.49 & $4.44^{39}$ \\
\hline
\end{tabular}


consist of three $-\mathrm{Al} / 3 \mathrm{O} / \mathrm{Al}$ - layers sandwiched with three to nine atomic layers of $\mathrm{Zn}$, thus containing two equivalent interfaces per supercell. The impact of a metallic buffer on the strength of the $\mathrm{Al}_{2} \mathrm{O}_{3} / \mathrm{Zn}$ interface is estimated by introducing one, two, or three $\mathrm{M}(111)$ atomic layers $(\mathrm{M}=\mathrm{Cr}, \mathrm{Fe}$, and $\mathrm{Ni})$ at the interface, whereas the effect of interface oxide is accounted for by adding a single $\mathrm{MO}_{x}(\mathrm{M}=\mathrm{Cr}, \mathrm{Fe}$, and $\mathrm{Ni})$ layer. Oxygen poor $(x=1)$, medium $(x=3 / 2)$, and rich $(x=2)$ compositions are chosen to systematically produce MO, $\mathrm{M}_{2} \mathrm{O}_{3}$, and $\mathrm{MO}_{2}$ stoichiometries, and the associated $+2,+3$, and +4 oxidation states of the cations M, characteristic for the considered transition metals, Fig. 1.

All configurations are thoroughly optimized in a series of structural relaxations starting from various initial layer stacking and various lattice registries at the interfaces between the materials (typically, 30-50 starting configurations per $\mathrm{Al}_{2} \mathrm{O}_{3} / \mathrm{MO}_{x} / \mathrm{Zn}$ superstructure). The lattice parameters within the interface plane are fixed to those calculated for bulk alumina, whereas the one perpendicular to the interface is optimized in order to relax distances between subsequent atomic planes. Positions of all atoms are optimized until all components of the residual forces are smaller than $0.01 \mathrm{eV} / \AA$. In all calculations, we employ a $\Gamma$-centered $8 \times 8 \times 1$ Monkhorst Pack grid for k-point sampling of the Brillouin zone of the $(1 \times 1)$ surface unit cell of alumina. Ionic charges are estimated with the partition scheme proposed by Bader. ${ }^{41,42}$

Moreover, as to estimate the effect of lateral strain due to the fixed in-plane lattice parameters, we compare results on the $\mathrm{Al}_{2} \mathrm{O}_{3} / \mathrm{ZnO} / \mathrm{Zn}$ system obtained with two alternative models. In addition to model I $\left[(1 \times 1)-\mathrm{Al}_{2} \mathrm{O}_{3}(0001) / /(\sqrt{3} \times \sqrt{3}) \mathrm{R} 30^{\circ}-\mathrm{ZnO}(0001) / /(\sqrt{3} \times\right.$ $\left.\sqrt{3}) \mathrm{R} 30^{\circ}-\mathrm{Zn}(0001)\right]$ used systematically for all systems, we also consider a much larger model II $\left[(2 \times 2)-\mathrm{Al}_{2} \mathrm{O}_{3}(0001) / /(3 \times 3)-\mathrm{ZnO}(0001) / /(2 \sqrt{3} \times 2 \sqrt{3}) \mathrm{R} 30^{\circ}-\mathrm{Zn}(0001)\right]$, characterized by a smaller mismatch between alumina and $\mathrm{ZnO}$ in-plane lattice parameters.

The adhesion strength at an A/B interface is estimated from the separation energy defined as:

$$
\mathrm{E}_{\mathrm{sep}}=-\left(\mathrm{E}_{\mathrm{A} / \mathrm{B}}-\mathrm{E}_{\mathrm{A}}-\mathrm{E}_{\mathrm{B}}\right) / 2 \mathrm{~S},
$$


where $\mathrm{E}_{\mathrm{A} / \mathrm{B}}, \mathrm{E}_{\mathrm{A}}$, and $\mathrm{E}_{\mathrm{B}}$ are the total energies of the $\mathrm{A} / \mathrm{B}$ heterostructure and separate $\mathrm{A}$ and B systems, respectively. Factor 2 accounts for the two equivalent A/B interfaces in each periodic unit cell and $\mathrm{S}$ is the interface area. Positions of all atoms in each of the separate systems A and B are optimized with the same computational settings and convergence criteria as the $\mathrm{A} / \mathrm{B}$ heterostructure. In the case of the $\mathrm{Zn} /$ alumina interface, we have checked that the adhesion energies deduced from the calculations on 6-alumina/9-zinc and 3-alumina/5-zinc superstructures differ by $0.1 \mathrm{~J} / \mathrm{m}^{2}$ only.

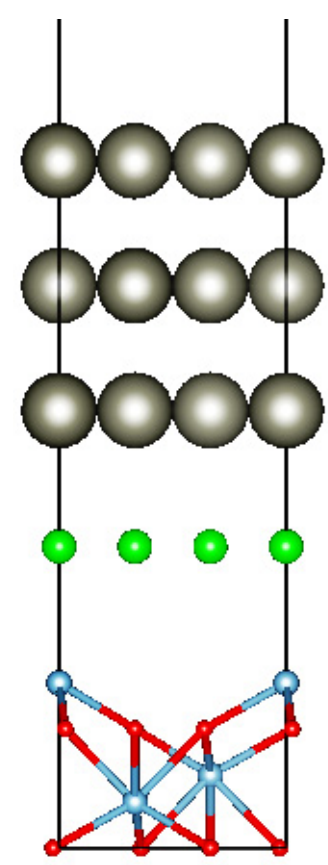

M

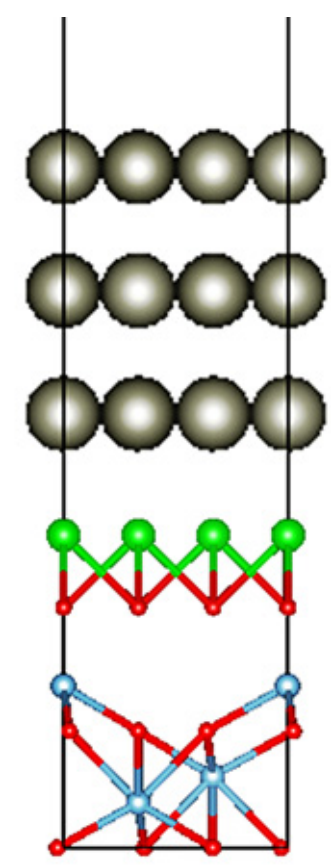

MO

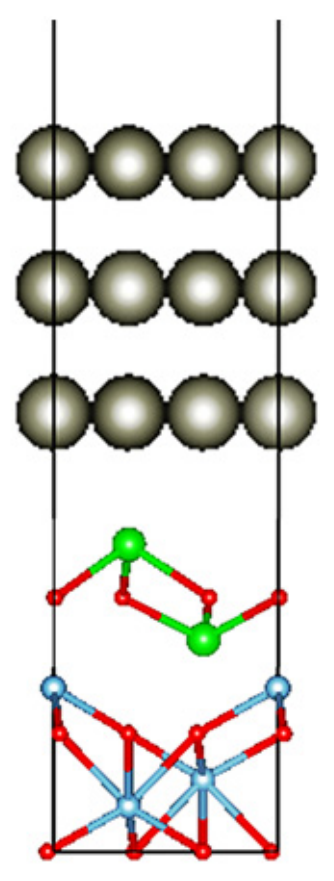

$\mathrm{M}_{2} \mathrm{O}_{3}$

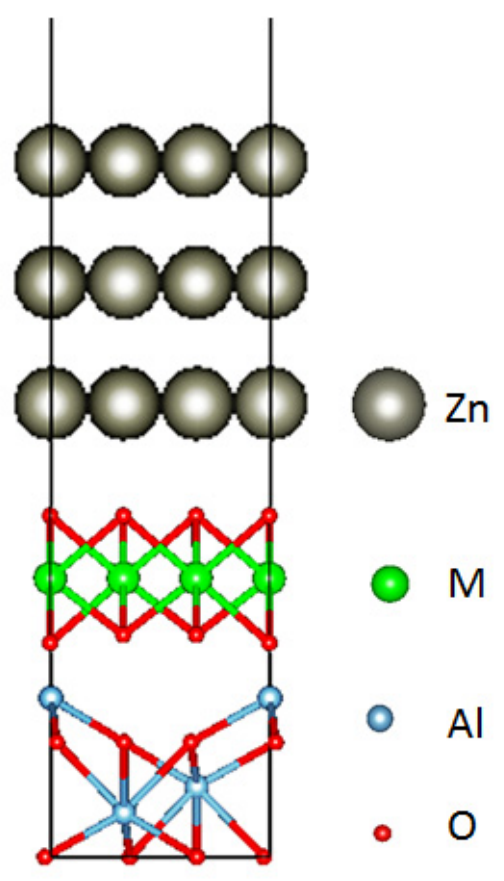

$\mathrm{MO}_{2}$

Figure 1: Schematic representation of the metallic $\mathrm{M}$ and oxide $\mathrm{MO}_{x}(\mathrm{x}=1,3 / 2$, and 2) buffers at the alumina/zinc interface.

To estimate the relative stability of interfaces with buffer layers of different stoichiometries we compare their formation energies as a function of oxygen conditions (oxygen chemical potential $\left.\mu_{O}\right)$ :

$$
\mathrm{E}_{\text {form }}\left(\Delta \mu_{O}\right)=\left[\mathrm{E}_{\mathrm{A} / \mathrm{MO}_{\mathrm{x}} / \mathrm{B}}-\mathrm{E}_{\mathrm{A}}-\mathrm{E}_{\mathrm{B}}-\mathrm{E}_{\mathrm{M}}-\mathrm{x}\left(\mathrm{E}_{\mathrm{O}_{2}} / 2+\Delta \mu_{O}\right)\right] / 2,
$$

where $\mu_{O}=\mathrm{E}_{\mathrm{O}_{2}} / 2+\Delta \mu_{O}$ and $\mathrm{E}_{\mathrm{A} / \mathrm{MO}_{\mathrm{x}} / \mathrm{B}}, \mathrm{E}_{\mathrm{M}}$, and $\mathrm{E}_{\mathrm{O}_{2}} / 2$ are the total energies of the $\mathrm{A} / \mathrm{MO}_{x} / \mathrm{B}$ heterostructure, the bulk metal $\mathrm{M}$, and a free $\mathrm{O}_{2}$ molecule, respectively. Factor 
2 accounts for the two equivalent interfaces in each periodic unit cell.

\section{Transition metals buffers at the $\mathrm{Al}_{2} \mathrm{O}_{3} / \mathrm{Zn}$ interface}

In this section we examine the effect of a metallic buffer on the adhesion at the $\mathrm{Al}_{2} \mathrm{O}_{3} / \mathrm{Zn}$ interface. To this goal one, two, or three (111) layers of metal $(\mathrm{M}=\mathrm{Cr}, \mathrm{Fe}$, and $\mathrm{Ni})$ are added to the interface and separation energies are evaluated at both the alumina/metal $\left(i_{1}\right)$ and metal/zinc $\left(\mathrm{i}_{2}\right)$ interfaces. We have previously shown that zinc adhesion at the Al-terminated alumina(0001) surface is very weak $\left(0.66 \mathrm{~J} / \mathrm{m}^{2}\right)$ due to the post-transition character of Zn. ${ }^{29}$ In particular, it is weaker than the separation energy calculated for bulk $\mathrm{Zn}\left(1.08 \mathrm{~J} / \mathrm{m}^{2}\right)$, representative for the strength of the zinc film itself. We will systematically refer to these two values in the following discussion.

Results in Table 2 show that metallic buffers substantially improve separation energies at both $\left(i_{1}\right)$ and $\left(i_{2}\right)$ interfaces, compared to those at the pure alumina/Zn interface and within bulk zinc. As a consequence, regardless the precise thickness of the buffer layer, all metals under consideration satisfactorily improve the strength of the alumina/Zn interface. In the following analysis we focus on the $3 \mathrm{ML}$ case, where the possible spurious in-plane tensile strain induced by the imposed coincidence structure is the most efficiently compensated by a tetragonal distortion in the metal buffer.

While the alumina/metal interface $\left(i_{1}\right)$ is characterized by separation energies system-

atically smaller than at the metal/zinc one $\left(i_{2}\right)$, the differences between $\mathrm{E}_{\text {sep }}$ calculated for different metal buffers at each of the two interfaces are relatively small. We note however a somewhat larger $\mathrm{E}_{\text {sep }}$ obtained at both $\left(\mathrm{i}_{1}\right)$ and $\left(\mathrm{i}_{2}\right)$ interfaces for Cr buffer and a somewhat smaller $\mathrm{E}_{\text {sep }}$ at $\left(\mathrm{i}_{1}\right)$ obtained with $\mathrm{Ni}$. Indeed, although considerably stronger compared to the pure alumina/Zn, the alumina/Ni interface is the most weakly adhering among the considered structures.

To understand the origin of such adhesion characteristics, in the following we analyze the 
Table 2: Separation energies $\mathrm{E}_{\mathrm{sep}}\left(\mathrm{J} / \mathrm{m}^{2}\right)$ calculated at the interface between one, two, and three metallic buffer layers and alumina $\left(i_{1}\right)$ or zinc $\left(i_{2}\right)$.

\begin{tabular}{lccc} 
Interface & $1 \mathrm{ML}$ & $2 \mathrm{ML}$ & $3 \mathrm{ML}$ \\
\hline$\left(\mathrm{i}_{1}\right)$ & & & \\
$\mathrm{Al}_{2} \mathrm{O}_{3} / \mathrm{Cr}$ & 1.83 & 2.02 & 2.12 \\
$\mathrm{Al}_{2} \mathrm{O}_{3} / \mathrm{Fe}$ & 1.62 & 1.79 & 1.88 \\
$\mathrm{Al}_{2} \mathrm{O}_{3} / \mathrm{Ni}$ & 1.75 & 1.83 & 1.78 \\
\hline$\left(\mathrm{i}_{2}\right)$ & & & \\
$\mathrm{Cr} / \mathrm{Zn}$ & 3.33 & 3.15 & 3.33 \\
$\mathrm{Fe} / \mathrm{Zn}$ & 3.03 & 3.10 & 2.99 \\
$\mathrm{Ni} / \mathrm{Zn}$ & 3.74 & 2.90 & 3.16 \\
\hline
\end{tabular}

number and the strength of interfacial bonds at the two interfaces.

\section{$3.1 \mathrm{Al}_{2} \mathrm{O}_{3} / \mathbf{M}$ interface $\left(\mathbf{i}_{1}\right)$}

At the contact between metal buffers and the stoichiometric alumina surface, we systematically find moderate or small interface charge transfers with no oxidation (reduction) of the deposited metal (oxide substrate). The non-reactive character of these interfaces is due to the large heat of formation of alumina compared to those of the considered metal oxides. Interaction strength at the $\mathrm{Al}_{2} \mathrm{O}_{3} / \mathrm{M}$ interface is relatively large for the metals in the middle of the transition series ( $\mathrm{Cr}$ ) but becomes smaller for the late and post-transition metals $(\mathrm{Ni}, \mathrm{Zn})$. This trend is consistent with the existing experimental evidence ${ }^{1}$ and is corroborated by the results of ab initio calculations of metal adsorption on alumina films and surfaces. ${ }^{20,22,29,43}$ Similar trends have also been reported for other non-reactive metal/oxide interfaces, such as, e.g., metal/MgO(100). ${ }^{44,45}$

Results of the bond analysis along the series, Tab. 3, suggest that the interface local structures and thus the interface characteristics are principally driven by a progressive decrease of the metal-oxygen (M-O) bond strength in the series. Indeed, in the case of stronger M-O bonds ( $\mathrm{Cr}, \mathrm{Fe}$ ), an interface structure with a maximal number of such bonds (six) and a single M-Al interfacial bond is favored (metal in Al-top site, see Fig. 2 left panel), and the resulting $\mathrm{E}_{\mathrm{sep}}$ are large. Conversely, in the case of $\mathrm{Ni}$ and $\mathrm{Zn}$, for which $\mathrm{M}-\mathrm{O}$ bonds are 
weaker, metal atoms occupy preferentially the O-top site, producing an interface structure with three $\mathrm{M}-\mathrm{O}$ and three $\mathrm{M}-\mathrm{Al}$ bonds (see Fig. 2 right panel) and a smaller $\mathrm{E}_{\text {sep }}$. According to our analysis, the increase of $\mathrm{E}_{\mathrm{sep}}$ between $\mathrm{Zn}$ and $\mathrm{Ni}$ is principally due to particularly short Ni-O bonds, close to their length in bulk nickel oxides.

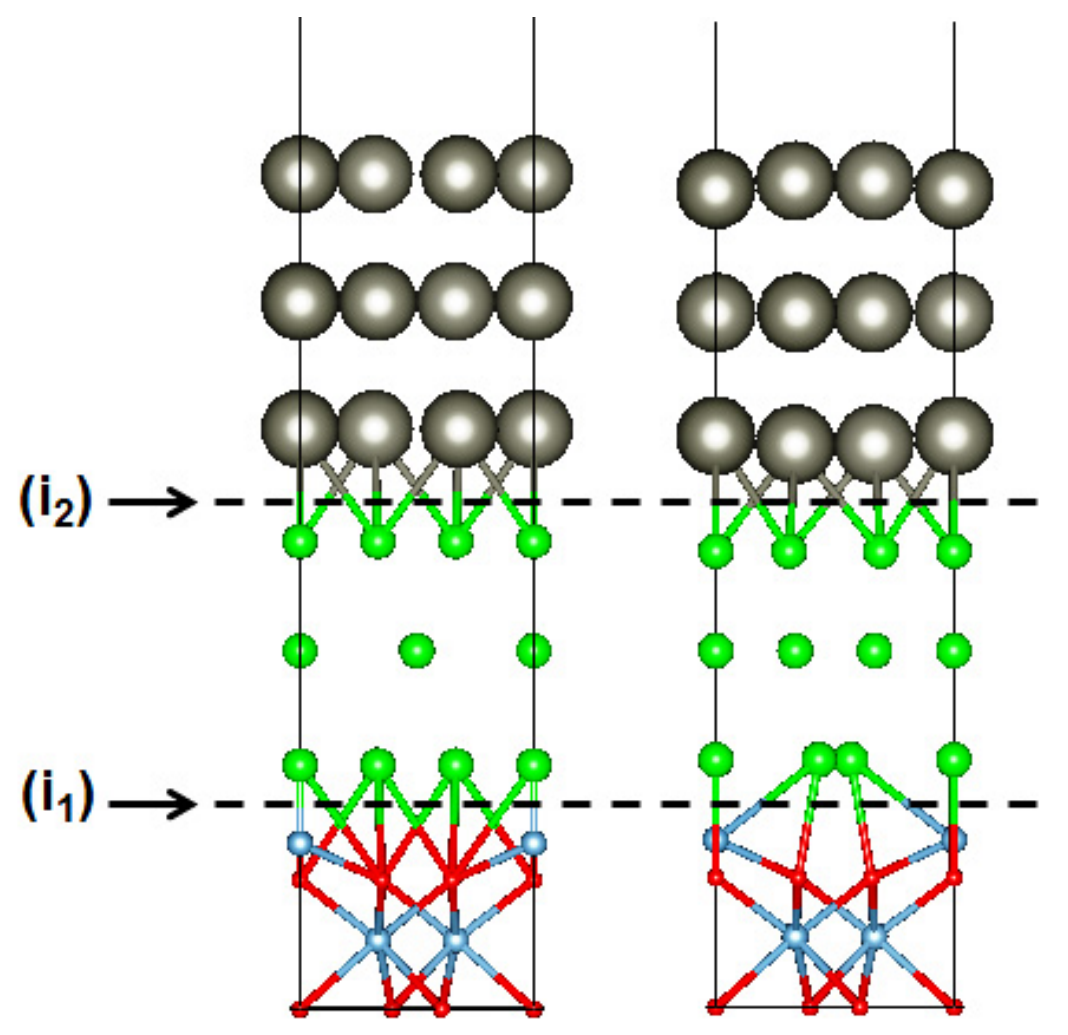

Figure 2: Schematic representation of the lowest energy configurations of $\mathrm{Al}_{2} \mathrm{O}_{3} / \mathrm{M} / \mathrm{Zn}$ superstructures in the cases of $\mathrm{Cr}$ and $\mathrm{Fe}$ (left), and Ni and Zn (right) highlighting interfacial bonds.

\section{$3.2 \mathrm{M} / \mathrm{Zn}$ interface $\left(\mathrm{i}_{2}\right)$}

For all transition metals, the separation energies at the $\mathrm{M} / \mathrm{Zn}$ interface are about three times larger compared to a $\mathrm{Zn} / \mathrm{Zn}$ interface $\left(1.08 \mathrm{~J} / \mathrm{m}^{2}\right)$. Adhesion is maximal for $\mathrm{Cr}$ and slightly smaller for $\mathrm{Fe}$, and $\mathrm{Ni}$ (Tab. 2). We find that metal atoms occupy systematically the hollow sites of the $\mathrm{Zn}(0001)$ surface, producing in all cases the same number (nine) of M-Zn interfacial bonds as shown in Fig. 2 and Tab. 4. As a consequence, the behavior of $\mathrm{E}_{\mathrm{sep}}$ is 
Table 3: Number (per unit cell) and lengths $(\AA)$ of bonds across the $\mathrm{Al}_{2} \mathrm{O}_{3} / \mathrm{M}$ interfaces $(\mathrm{M}=\mathrm{Cr}, \mathrm{Fe}$ and $\mathrm{Ni})$ obtained for $3 \mathrm{ML}$ metal buffers. Al-top and O-top are the preferential sites of metal atoms with respect to the alumina substrate. Results for the $\mathrm{Al}_{2} \mathrm{O}_{3} / \mathrm{Zn}$ interface are shown as a reference and the corresponding separation energies $E_{\text {sep }}\left(\mathrm{J} / \mathrm{m}^{2}\right)$ are recalled in the last column.

\begin{tabular}{lccc} 
Interface $\left(\mathrm{i}_{1}\right)$ & $\begin{array}{c}\mathrm{d}(\mathrm{M}-\mathrm{O}) \\
(\AA)\end{array}$ & $\begin{array}{c}\mathrm{d}(\mathrm{Al}-\mathrm{M}) \\
(\AA)\end{array}$ & $\begin{array}{c}\mathrm{E}_{\text {sep }} \\
\left(\mathrm{J} / \mathrm{m}^{2}\right)\end{array}$ \\
\hline $\mathrm{Al}-$ top & & & \\
$\mathrm{Al}_{2} \mathrm{O}_{3} / \mathrm{Cr}$ & $6 \times 2.58$ & $1 \times 2.57$ & 2.12 \\
$\mathrm{Al}_{2} \mathrm{O}_{3} / \mathrm{Fe}$ & $6 \times 2.53$ & $1 \times 2.44$ & 1.88 \\
\hline $\mathrm{O}-$ top & & & \\
$\mathrm{Al}_{2} \mathrm{O}_{3} / \mathrm{Ni}$ & $3 \times 2.11$ & $3 \times 2.51$ & 1.78 \\
$\mathrm{Al}_{2} \mathrm{O}_{3} / \mathrm{Zn}$ & $3 \times 2.71$ & $3 \times 2.86$ & 0.66 \\
\hline
\end{tabular}

to be associated with changes of the M-Zn bond strength along the series. If estimated from a geometric average of (bulk) M-M and Zn-Zn bond energies, M-Zn bond strength varies along the series as the metal M cohesive energy, producing stronger $\mathrm{Cr}-\mathrm{Zn}$ and Fe-Zn bonds, somewhat weaker Ni-Zn bonds, and particularly weak Zn-Zn bonds. The model accounts thus correctly for the overall trend, the maximal strength in the case of $\mathrm{Cr}$, and the dramatic decrease in the case of Zn.

Table 4: Number (per unit cell) and lengths of bonds $(\AA)$ across the $\mathrm{M} / \mathrm{Zn}$ interfaces $(\mathrm{M}=\mathrm{Cr}, \mathrm{Fe}$, and $\mathrm{Ni})$ obtained for $3 \mathrm{ML}$ metal buffers. Corresponding results for the $\mathrm{Zn} / \mathrm{Zn}$ interface are shown as a reference and the separation energies $E_{\text {sep }}\left(\mathrm{J} / \mathrm{m}^{2}\right)$ are recalled in the last column.

\begin{tabular}{lcc} 
Interface $\left(\mathrm{i}_{2}\right)$ & $\mathrm{d}(\mathrm{M}-\mathrm{Zn})(\AA)$ & $\mathrm{E}_{\text {sep }}\left(\mathrm{J} / \mathrm{m}^{2}\right)$ \\
\hline $\mathrm{Cr} / \mathrm{Zn}$ & $6 \times 2.59,3 \times 2.99$ & 3.33 \\
$\mathrm{Fe} / \mathrm{Zn}$ & $6 \times 2.54,3 \times 2.95$ & 2.99 \\
$\mathrm{Ni} / \mathrm{Zn}$ & $9 \times 2.51$ & 3.16 \\
$\mathrm{Zn} / \mathrm{Zn}$ & $9 \times 2.78$ & 1.08 \\
\hline
\end{tabular}

To summarize, we have shown that a transition metal buffer improves efficiently the strength of an alumina/Zn interface. Separation energies at the alumina/M are larger in the case of $\mathrm{Cr}$, driven by the large strength of the corresponding M-O bonds. At the $\mathrm{M} / \mathrm{Zn}$ interface the best adhesion is also predicted for the Cr buffer, characterized by strong Cr-Zn bonds, driven by the large cohesion of Cr. Conversely, the relatively weak adhesion at both 
alumina/Zn and $\mathrm{Zn} / \mathrm{Zn}$ interfaces is principally due to the post-transition character and low cohesion of zinc which result in relatively weak Zn-O and Zn-Zn bonds.

\section{Oxidized transition metal buffers at the $\mathrm{Al}_{2} \mathrm{O}_{3} / \mathrm{Zn}$ interface}

In this section, we estimate the effect of oxidation of the metallic buffer on the interfacial strength. To this goal a single $\mathrm{MO}_{x}$ oxide layer $(\mathrm{M}=\mathrm{Cr}, \mathrm{Fe}$, and $\mathrm{Ni})$ is introduced at the $\mathrm{Al}_{2} \mathrm{O}_{3} / \mathrm{Zn}$ interface and its composition is systematically varied from oxygen poor $(x=1)$, through medium $(x=3 / 2)$, up to oxygen rich $(x=2)$. Moreover, a single interfacial $\mathrm{ZnO}$ layer (Zn oxidation state +2 ) is also considered as to represent the effect of zinc oxidation at the interface with alumina and to provide a reference for the analysis of the effect of buffer oxidation.

Following the methodology of the previous section we systematically evaluate interface separation energies at both oxide/oxide $\mathrm{Al}_{2} \mathrm{O}_{3} / \mathrm{MO}_{\mathrm{x}}\left(\mathrm{i}_{1}\right)$ and oxide/zinc $\mathrm{MO}_{\mathrm{x}} / \mathrm{Zn}\left(\mathrm{i}_{2}\right)$ most stable interface configurations (Fig. 3). Additionally, as to account for changes of zinc cohesion in the direct interface vicinity, the separation energies between the first and the second metallic Zn layers $\left(i_{3}\right)$ are also evaluated. Table 5 summarizes our results and recalls the separation energies obtained for the corresponding (3 ML) metallic buffers and for the pure alumina/zinc interface.

Figure2.eps Results reported in Tab. 5 show that the oxidation of the metal buffer may be beneficial or detrimental to the interface adhesion, depending on the oxide stoichiometry and the interfacial atomic configuration. However, for all considered oxide buffers, we obtain an overall improvement of interface strength with respect to the critical value of $0.66 \mathrm{~J} / \mathrm{m}^{2}$ found at the pure alumina/zinc interface. We note that a given buffer rarely produces the optimal separation energies simultaneously at both $\left(i_{1}\right)$ and $\left(i_{2}\right)$ interfaces. 


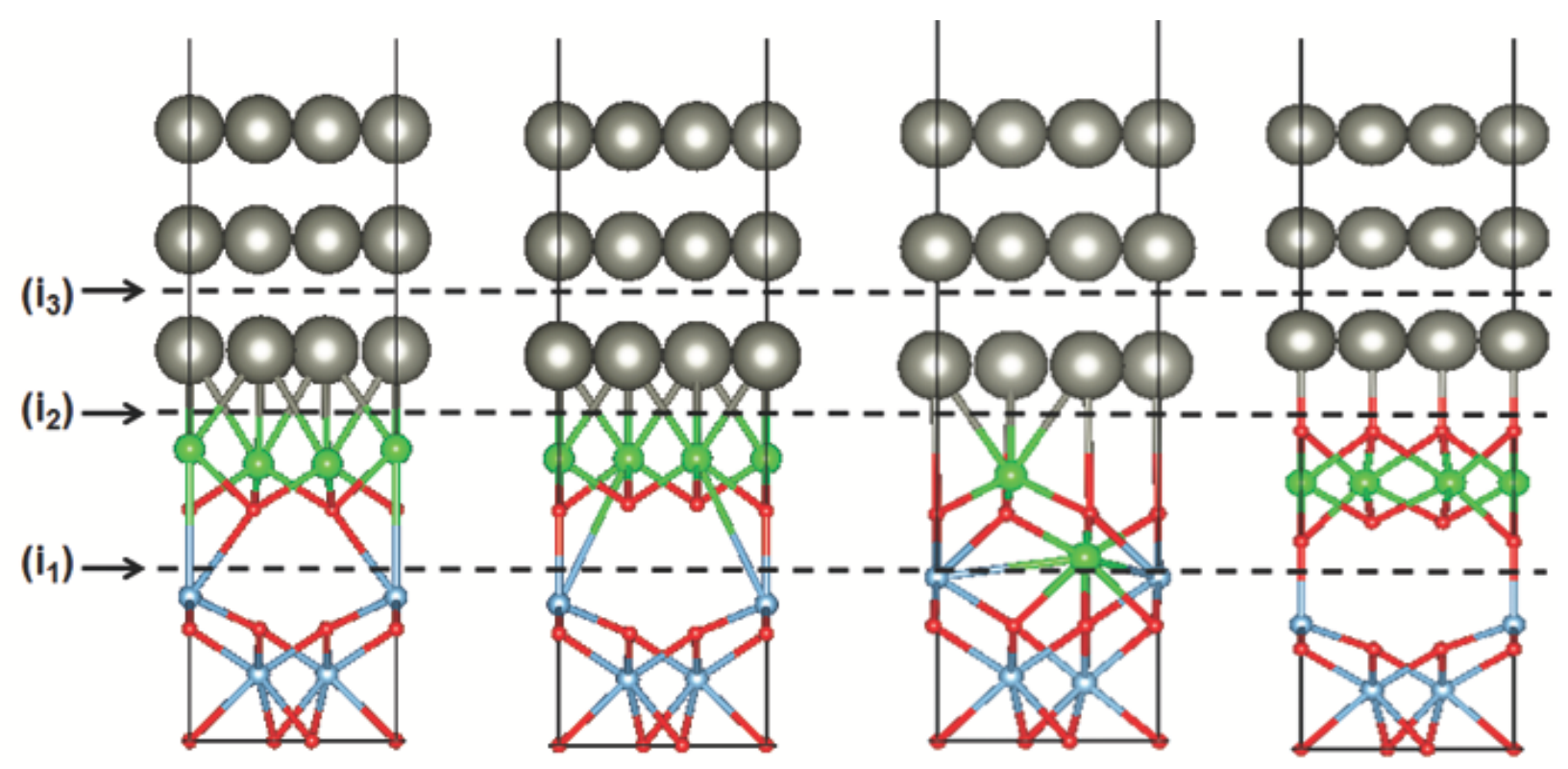

Figure 3: Schematic representation of the lowest energy configurations of $\mathrm{Al}_{2} \mathrm{O}_{3} / \mathrm{MO}_{\mathrm{x}} / \mathrm{Zn}$ superstructures in the cases of (left to right): $\mathrm{O}-\mathrm{Cr}$, O-Fe and $\mathrm{O}-\mathrm{Ni}, \mathrm{M}_{2} \mathrm{O}_{3}$, and $\mathrm{MO}_{2}$ buffers. Interfacial bonds are highlighted.

Table 5: Separation energies $\left(\mathrm{J} / \mathrm{m}^{2}\right)$ calculated for $\mathrm{Al}_{2} \mathrm{O}_{3} / \mathrm{MO}_{\mathrm{x}} / \mathrm{Zn}$ systems at $\mathrm{Al}_{2} \mathrm{O}_{3} / \mathrm{MO}_{\mathrm{x}}\left(\mathrm{i}_{1}\right), \mathrm{MO}_{\mathrm{x}} / \mathbf{Z n}\left(\mathbf{i}_{2}\right)$, and $\mathbf{Z n} / \mathbf{Z n}\left(\mathbf{i}_{3}\right)$ interfaces. First column gives the composition of the $\mathrm{MO}_{\mathrm{x}}$ buffers. In the case of $\mathrm{ZnO}$ buffers results are given for both interface models I and II. Results obtained for 3ML metallic buffers and for the pure alumina/zinc interface are recalled for completeness.

\begin{tabular}{cccc} 
Buffer & $\left(\mathrm{i}_{1}\right)$ & $\left(\mathrm{i}_{2}\right)$ & $\left(\mathrm{i}_{3}\right)$ \\
\hline $\mathrm{O}-\mathrm{Cr}$ & 0.73 & 4.00 & 1.93 \\
$\mathrm{Cr}-\mathrm{O}_{3}-\mathrm{Cr}$ & 3.19 & 1.01 & 1.18 \\
$\mathrm{O}-\mathrm{Cr}-\mathrm{O}$ & 1.32 & 1.96 & 0.96 \\
$\mathrm{Cr}$ & 2.12 & 3.33 & \\
\hline $\mathrm{O}-\mathrm{Fe}$ & 1.08 & 1.88 & 1.73 \\
$\mathrm{Fe}-\mathrm{O}_{3}-\mathrm{Fe}$ & 2.47 & 1.25 & 1.02 \\
$\mathrm{O}-\mathrm{Fe}-\mathrm{O}$ & 1.31 & 2.00 & 0.92 \\
$\mathrm{Fe}$ & 1.88 & 2.99 & \\
\hline $\mathrm{O}-\mathrm{Ni}$ & 1.36 & 2.14 & 1.58 \\
$\mathrm{Ni}-\mathrm{O}_{3}-\mathrm{Ni}$ & 2.62 & 1.60 & 0.94 \\
$\mathrm{O}-\mathrm{Ni}-\mathrm{O}$ & 1.35 & 2.02 & 0.96 \\
$\mathrm{Ni}$ & 1.78 & 3.16 & \\
\hline $\mathrm{Zn}-\mathrm{O} \mathrm{I}$ & 1.37 & 0.97 & 1.01 \\
$\mathrm{Zn}-\mathrm{O} \mathrm{II}$ & 1.53 & 0.78 & 1.35 \\
$\mathrm{Zn}$ & 0.66 & 1.08 & 1.08 \\
\hline
\end{tabular}


Table 6: Number [per $(1 \times 1)$ unit cell] and lengths $(\AA)$ of bonds across the $\mathrm{Al}_{2} \mathrm{O}_{3} / \mathrm{MO}_{\mathrm{x}}$ interfaces. Corresponding separation energies $\mathrm{E}_{\text {sep }}\left(\mathrm{J} / \mathrm{m}^{2}\right)$ are recalled in the last column. In the case of $\mathrm{ZnO}$ buffers results are given for both interface models I and II.

\begin{tabular}{ccccc}
$\left(\mathrm{i}_{1}\right)$ & $\mathrm{d}(\mathrm{M}-\mathrm{O})(\AA)$ & $\mathrm{d}(\mathrm{Al}-\mathrm{O})(\AA)$ & $\mathrm{d}(\mathrm{Al}-\mathrm{M})(\AA)$ & $\mathrm{E}_{\text {sep }}\left(\mathrm{J} / \mathrm{m}^{2}\right)$ \\
\hline $\mathrm{O}-\mathrm{Cr}$ & 0 & $3 \times 2.30$ & $1 \times 2.97$ & 0.73 \\
$\mathrm{Cr}-\mathrm{O}_{3}-\mathrm{Cr}$ & $3 \times 2.05$ & $3 \times 1.96$ & $1 \times 2.50,3 \times 2.80$ & 3.19 \\
$\mathrm{O}-\mathrm{Cr}-\mathrm{O}$ & 0 & $1 \times 1.87$ & 0 & 1.32 \\
$\mathrm{Cr}$ & $6 \times 2.58$ & 0 & $1 \times 2.57$ & 2.12 \\
\hline $\mathrm{O}-\mathrm{Fe}$ & 0 & $1 \times 1.90$ & $1 \times 3.34,2 \times 3.37$ & 1.08 \\
$\mathrm{Fe}-\mathrm{O}_{3}-\mathrm{Fe}$ & $3 \times 2.01$ & $3 \times 1.94$ & $1 \times 2.45,3 \times 2.79$ & 2.47 \\
$\mathrm{O}-\mathrm{Fe}-\mathrm{O}$ & 0 & $1 \times 1.89$ & 0 & 1.31 \\
$\mathrm{Fe}$ & $6 \times 2.53$ & 0 & $1 \times 2.44$ & 1.88 \\
\hline $\mathrm{O}-\mathrm{Ni}$ & 0 & $1 \times 1.86$ & $3 \times 3.33$ & 1.36 \\
$\mathrm{Ni}-\mathrm{O}{ }_{3}-\mathrm{Ni}$ & $3 \times 2.02$ & $3 \times 1.96$ & $1 \times 2.43,3 \times 2.79$ & 2.62 \\
$\mathrm{O}-\mathrm{Ni}-\mathrm{O}$ & 0 & $1 \times 1.87$ & 0 & 1.35 \\
$\mathrm{Ni}$ & $3 \times 2.11$ & 0 & $3 \times 2.51$ & 1.78 \\
\hline $\mathrm{Zn}-\mathrm{O} \mathrm{I}$ & $3 \times 2.90$ & $1 \times 1.86$ & $3 \times 3.13$ & 1.37 \\
$\mathrm{Zn}-\mathrm{O} \mathrm{II}$ & $3 / 4 \times 2.12$, & $1 / 4 \times 1.82$, & $3 / 4 \times 2.82,2 / 4 \times 2.86$, & 1.53 \\
& $3 / 4 \times 2.40$ & $3 / 4 \times 1.88$ & $2 / 4 \times 2.98$ & \\
$\mathrm{Zn}$ & $3 \times 2.71$ & 0 & $3 \times 2.86$ & 0.66 \\
\hline
\end{tabular}

\section{1 $\mathrm{Al}_{2} \mathrm{O}_{3} / M O_{x}$ interface $\left(\mathbf{i}_{1}\right)$}

At $\left(i_{1}\right)$, the largest adhesion is found when transition metal atoms $M$ are in contact with alumina (alumina/M and alumina/ $\mathrm{M}-\mathrm{O}_{3}-\mathrm{M}$ configurations) while an oxygen contact with alumina, whatever the oxide stoichiometry, is detrimental to adhesion (alumina/O-M and alumina/O-M-O configurations), Tab. 5. For the three transition metals, the $\mathrm{M}_{-} \mathrm{O}_{3}-\mathrm{M}$ buffer systematically produces the optimal adhesion, larger than for the corresponding metallic buffers. For this oxide stoichiometry, the best performance is obtained with Cr, while the interface strength with $\mathrm{Fe}$ and $\mathrm{Ni}$ is weaker. Interestingly, zinc oxidation produces a larger adhesion compared to the pure alumina/zinc interface and similar or larger compared to O-Ni, O-Fe, and O-Cr buffers.

Interfacial metal-oxygen bonds $(\mathrm{M}-\mathrm{O}$ and $\mathrm{Al}-\mathrm{O})$ formed at the alumina/ $\mathrm{MO}_{\mathrm{x}}$ interface have an iono-covalent character and their strength can be qualitatively estimated from the corresponding bulk oxide formation enthalpies. ${ }^{1,29}$ The metal-oxygen bonds are the strongest 
in the case of alumina, and there is a progressive decrease of their strength along the transition series.

Table 7: Number [per $(1 \times 1)$ unit cell] and lengths $(\AA)$ of bonds across the $\mathrm{MO}_{\mathrm{x}} / \mathrm{Zn}$ interfaces. Corresponding separation energies $\mathrm{E}_{\text {sep }}\left(\mathrm{J} / \mathrm{m}^{2}\right)$ are recalled in the last column. In the case of $\mathrm{ZnO}$ buffers results are given for both interface models I and II.

\begin{tabular}{cccc}
$\left(\mathrm{i}_{2}\right)$ & $\mathrm{d}(\mathrm{M}-\mathrm{Zn})(\AA)$ & $\mathrm{d}(\mathrm{Zn}-\mathrm{O})(\AA)$ & $\mathrm{E}_{\text {sep }}\left(\mathrm{J} / \mathrm{m}^{2}\right)$ \\
\hline $\mathrm{O}-\mathrm{Cr}$ & $3 \times 2.59,6 \times 2.78$ & 0 & 4.00 \\
$\mathrm{Cr}-\mathrm{O}_{3}-\mathrm{Cr}$ & $3 \times 2.75$ & $3 \times 2.92$ & 1.01 \\
$\mathrm{O}-\mathrm{Cr}-\mathrm{O}$ & 0 & $3 \times 2.04$ & 1.96 \\
$\mathrm{Cr}$ & $6 \times 2.59,3 \times 2.99$ & 0 & 3.33 \\
\hline $\mathrm{O}-\mathrm{Fe}$ & $9 \times 2.63$ & 0 & 1.88 \\
$\mathrm{Fe}-\mathrm{O}_{3}-\mathrm{Fe}$ & $3 \times 2.57$ & $3 \times 2.59$ & 1.25 \\
$\mathrm{O}-\mathrm{Fe}-\mathrm{O}$ & 0 & 0 & 2.02 \\
$\mathrm{Fe}$ & $6 \times 2.54,3 \times 2.95$ & 0 & 2.99 \\
\hline $\mathrm{O}-\mathrm{Ni}$ & $9 \times 2.61$ & $3 \times 2.14$ & 2.14 \\
$\mathrm{Ni}-\mathrm{O}{ }_{3}-\mathrm{Ni}$ & $3 \times 2.48$ & 0 & 1.60 \\
$\mathrm{O}-\mathrm{Ni}-\mathrm{O}$ & 0 & $2 \times 2.08$ & 2.02 \\
$\mathrm{Ni}$ & $9 \times 2.51$ & 0 & 3.10 \\
\hline $\mathrm{Zn}-\mathrm{O} \mathrm{I}$ & 0 & $01 / 4 \times 2.17$ & 0.97 \\
$\mathrm{Zn}-\mathrm{O} \mathrm{II}$ & $3 / 4 \times 2.54,3 / 4 \times 2.89$, & $1 / 4 \times 2.07$, & 0.78 \\
$\mathrm{Zn}$ & $3 / 4 \times 2.98$ & $2.01,1 / 4$ & \\
\hline
\end{tabular}

The systematically most adhesive alumina/ $\mathrm{M}-\mathrm{O}_{3}-\mathrm{M}$ interfaces are characterized by the largest number of interfacial $\mathrm{M}-\mathrm{O}$ and $\mathrm{Al}-\mathrm{O}$ bonds (three and three, respectively). When compared to the alumina/purely metallic interfaces, the alumina/ $\mathrm{M}_{-} \mathrm{O}_{3}-\mathrm{M}$ interfaces produce larger adhesion energies due to the fact that additional Al-O bonds, which are stronger than M-O ones, are formed.

On the contrary, the performance of O-M and O-M-O buffers is poor compared to the corresponding pure metal buffers. The weak adhesion at alumina/O-M interface is to be linked directly to the small number of Al-O and M-O bonds (Tab. 6). Indeed, the alumina/OM stacking sequence, which is favored for all considered transition metals, leads to an absence of interfacial M-O bond and to a small number of Al-O bonds at the interfaces (three for O-Cr and one for both O-Fe and O-Ni buffers). Moreover, in the case of O-Cr buffer, the 
three Al-O bonds are expanded with respect to their bulk $\mathrm{Al}_{2} \mathrm{O}_{3}$ length and are thus weak.

Oxidation of $\mathrm{Zn}$ at the interface with $\mathrm{Al}_{2} \mathrm{O}_{3}$ improves the adhesion strength of the bare alumina/zinc interface principally due to the formation of interfacial Al-O bonds. Let us note that the difference between models I and II is relatively small. The somewhat larger alumina/Zn-O adhesion found with the model II despite the smaller number of interface Zn-O bonds is principally driven a reduction of interface constrain allowing shorter Zn-O bonds.

\section{2 $M O_{x} / \mathrm{Zn}$ interface $\left(\mathbf{i}_{2}\right)$}

Separation energies at the $\left(\mathrm{i}_{2}\right)$ interface suggest that in all cases (but $\mathrm{O}-\mathrm{Cr} / \mathrm{Zn}$ ) oxidation of the buffer layer is strongly detrimental to adhesion (Tab. 5. The adhesion weakening is systematically the strongest for the $\mathrm{M}_{-} \mathrm{O}_{3}-\mathrm{M}$ oxide layers. We note that in the case of $\mathrm{CrO}_{x}$ the adhesion is particularly sensitive to the buffer stoichiometry and ranges from very strong for $\mathrm{Cr}-\mathrm{O}$ to especially weak for $\mathrm{Cr}_{-} \mathrm{O}_{3}-\mathrm{Cr}$. Conversely, a relatively equilibrated performance at this interface is obtained for the $\mathrm{NiO}_{x}$ buffers.

The systematic decrease of adhesion at $\mathrm{M}_{-} \mathrm{O}_{3}-\mathrm{M} / \mathrm{Zn}$ and $\mathrm{O}-\mathrm{M}-\mathrm{O} / \mathrm{Zn}$ interfaces with respect to the favorable metal/Zn case obtained with purely metallic buffers is principally driven by the reduction of the number of metal-zinc bonds at the interface, which is not compensated by the formation of relatively weak interfacial Zn-O bonds (Tab. 7). Indeed, compared to nine metal-zinc bonds formed at interfaces with metallic buffers, we find only three such bonds in the case of $\mathrm{M}_{2} \mathrm{O}_{3} / \mathrm{Zn}$ buffers, and no metal-zinc bonds for O-M-O ones, leading in all these cases to a substantial reduction of adhesion at $\left(\mathrm{i}_{2}\right)$. Formation of additional Zn-O bonds across the interface compensates to some extent for the loss of adhesion. However, in all (but the O-M-O) buffers there is a considerable expansion of the Zn-O bonds compared to their bulk values, which leads to an only moderate adhesion gain.

Interestingly, at the $\mathrm{O}-\mathrm{Cr} / \mathrm{Zn}$ interface, where the number and length of M-Zn bonds is preserved with respect to the case of the metallic Cr buffer, we find a non-negligible increase 
of adhesion, while at the similar $\mathrm{O}-\mathrm{Fe} / \mathrm{Zn}$ and $\mathrm{O}-\mathrm{Ni} / \mathrm{Zn}$ interfaces (the same number of M-Zn bonds), adhesion strength decreases. These fine effects go beyond the present bond analysis likely due to the contribution induced by the polarization of the metal oxide films and the strong coupling between their structure (rumpling) and the charge transfer across the interface. ${ }^{46,47}$

It is also worth noticing that the presence of $\mathrm{ZnO}$ at the interface results in the formation of relatively weak interfacial $\mathrm{Zn}-\mathrm{O}$ bonds at the $\mathrm{ZnO} / \mathrm{Zn}$ interface $\left(\mathrm{i}_{2}\right)$. Similarly to the cases discussed above, this interface is characterized by a smaller adhesion energy compared to the purely metallic $\mathrm{Zn} / \mathrm{Zn}$ one $\left(1.08 \mathrm{~J} / \mathrm{m}^{2}\right)$ due to the reduction of the number of $\mathrm{Zn} / \mathrm{Zn}$ bonds. The adhesion energy deduced from the model II is smaller than that obtained with model I and is only slightly larger than the critical value of $0.66 \mathrm{~J} / \mathrm{m}^{2}$, characteristic of the pure alumina/Zn interface. The effect is driven by the distortion of the $\mathrm{ZnO}$ film induced by the interaction with alumina, which results in a large reduction of the number of Zn-O bonds at the $\mathrm{ZnO} / \mathrm{Zn}$ interface in model II.

Finally, it is worth pointing out that the presence of an oxide buffer may alter the cohesion of zinc in the direct vicinity of the Figure2.epsinterface $\left(\mathrm{i}_{3}\right)$, compared to $1.08 \mathrm{~J} / \mathrm{m}^{2}$ obtained for the pure alumina/zinc interface. The particularly detrimental decrease of ZnZn bonding which occurs in the presence of $\mathrm{O}-\mathrm{M}-\mathrm{O}, \mathrm{Fe}-\mathrm{O}_{3}-\mathrm{Fe}, \mathrm{Ni}-\mathrm{O}_{3}-\mathrm{Ni}$, and $\mathrm{Zn}-\mathrm{O}$ is to be associated with a positive charging of $\mathrm{Zn}$ due to an oxygen excess in the buffer layer. Conversely, oxygen-poor buffers with transition metal in contact with zinc at the $\left(\mathrm{i}_{2}\right)$ interface tend to improve the cohesion within the neighboring zinc.

To summarize, we have shown that the oxidation of transition metal buffer may be beneficial or detrimental to the interface adhesion, which nevertheless in all considered cases remains larger than at the pure alumina/zinc interface. The bond analysis shows that the strength of the alumina/oxide interface is directly driven by the number of metal-oxygen bonds, which is systematically maximized by the best adhesive $\mathrm{M}_{-}-\mathrm{O}_{3}-\mathrm{M}$ buffer configurations, especially in the case of $\mathrm{Cr}$. Oxidation of the metal buffer systematically reduces the strength 
of the oxide/zinc interface, principally due to the reduction of the number of metal-zinc bonds, which is hardly compensated by the formation of the Zn-O ones. It is worth noting that zinc oxidation at the alumina/zinc interface results in a relatively weak adhesion between $\mathrm{ZnO}$ and $\mathrm{Zn}$, comparable to that at the alumina/Zn one.

\section{Discussion}

Our computational results predict a large potentiality of buffer layers for tuning and enhancing the adhesion of the weakly interacting alumina/zinc interface. In particular, buffers composed of metals from the middle of the transition series are expected to spectacularly improve the strength of this interface. However, we have also shown that an oxidation of the metal buffer reduces in most cases its favorable effect. Indeed, while for some oxide stoichiometries a good adhesion can be preserved at either alumina/buffer (i $\left.i_{1}\right)$ or buffer/Zn $\left(i_{2}\right)$ interface, none of the considered oxide buffers offers global results close to or better than those of the metallic ones.

Our bond analysis has pointed out the key role of strong metal-oxygen (M-O) bonds for the adhesion at the alumina/buffer interface and of strong metal-zinc (M-Zn) ones for the adhesion at buffer/zinc interface. Very clearly, the growing oxygen content in the buffer layer reduces the number of such bonds at either one or the other, or at both $\left(\mathrm{i}_{1}\right)$ and $\left(\mathrm{i}_{2}\right)$ interfaces. This general trend is particularly well pronounced in the case of $\mathrm{CrO}_{x}$ buffers, where a dramatic decrease of adhesion with respect to the purely metallic buffer is in all cases directly linked to the presence of oxygen at either alumina/ $\mathrm{CrO}_{x}$ or $\mathrm{CrO}_{x} /$ zinc interface.

Based on this analysis, with the goal to identify possible ways of healing the detrimental effect of buffer oxidation, we have reconsidered the $\mathrm{O}-\mathrm{Cr}$ and $\mathrm{Cr}_{-} \mathrm{O}_{3}-\mathrm{Cr}$ buffers. In each case we have inserted an additional atomic Cr layer at the interface which suffered from adhesion weakening. The results summarized in Tab. 8 clearly demonstrate that even a single additional Cr layer can bring the adhesion back to the level obtained with the purely 
Table 8: Separation energies $\left(\mathrm{J} / \mathrm{m}^{2}\right)$ calculated for $\mathrm{Al}_{2} \mathrm{O}_{3} / \mathrm{CrO}_{x} / \mathrm{Zn}$ interfaces with and without an additional interfacial $\mathrm{Cr}$ layer. Both alumina/buffer $\left(i_{1}\right)$ and buffer $/ \mathrm{Zn}\left(\mathrm{i}_{2}\right)$ interfaces have been considered. Position of the additional $\mathrm{Cr}$ layer with respect to the oxide buffer is indicated in bold. Corresponding results for purely metallic $\mathrm{Cr}$ buffer are recalled.

\begin{tabular}{lcc} 
Buffer & $\left(\mathrm{i}_{1}\right)$ & $\left(\mathrm{i}_{2}\right)$ \\
\hline \multicolumn{1}{c}{$\mathrm{O}-\mathrm{Cr}$} & 0.73 & 4.00 \\
$\mathrm{Cr} / \mathrm{O}-\mathrm{Cr}$ & 2.41 & 4.77 \\
\hline $\mathrm{Cr}-\mathrm{O}_{3}-\mathrm{Cr}$ & 3.19 & 1.01 \\
$\mathrm{Cr}-\mathrm{O}_{3}-\mathrm{Cr} / \mathrm{Cr}$ & 2.98 & 3.10 \\
\hline $\mathrm{Cr}$ & 2.12 & 3.33 \\
\hline
\end{tabular}

metallic buffer. We note that for both $\mathrm{O}-\mathrm{Cr}$ and $\mathrm{Cr}-\mathrm{O}_{3}-\mathrm{Cr}$ buffers, the $\left(\mathrm{i}_{1}\right)$ and $\left(\mathrm{i}_{2}\right)$ interfaces are weakly coupled, such that adhesion change at one of them affects only little the other.

These results further confirm the validity of the conclusions deduced from the bond analysis and generalize the predicted favorable effect of purely metallic buffers over buffers of a more complex composition, provided that they remain oxygen-poor. Importantly and consistently with the local character of interfacial M-O and M-Zn bonds, the results show that, even for the considered ultra-thin buffers, the adhesion is not solely a function of the overall buffer stoichiometry but is driven by the local atomic configuration at each of the interfaces.

The above discussion brings also up the question of possible tuning of the oxidation state of a metallic buffer, e.g., by adjusting the oxygen conditions during buffer formation. For the series of metallic and oxidized buffers considered in the present study, Figure 4 displays the values of the oxygen chemical potential $\Delta \mu_{O}$ at which the calculated oxidized buffers become thermodynamically favored over the corresponding metallic ones. As a reference, corresponding values of $\Delta \mu_{O}$ deduced from the experimental standard enthalpies of oxide formation $\Delta_{f} H^{\circ}(298.15 K)^{48,49}$ (per oxygen atom) are also given. Systematically, metals from the middle of the first transition series, such as Cr, are more active towards oxygen and tend to form oxides already in largely oxygen-poor environment $\left(\Delta \mu_{O} \sim-4.0 \mathrm{eV}\right)$, while late and post-transition metals preserve their metallic form until considerably more oxygen-rich 
conditions $\left(\Delta \mu_{O} \sim-3.0--2.5 \mathrm{eV}\right.$ for $\mathrm{Fe}, \mathrm{Ni}$ and $\left.\mathrm{Zn}\right)$. We note that the similarity of the two sets of results shows that neither the ultra-thin thickness of the considered buffers nor the presence of interfaces with alumina and zinc nor the idealized character of the computed interfaces alter the known trend along the series of metals. Somewhat larger difference in the case of $\mathrm{Zn}$ is likely due to the structural flexibility of the $\mathrm{ZnO}$ layer.

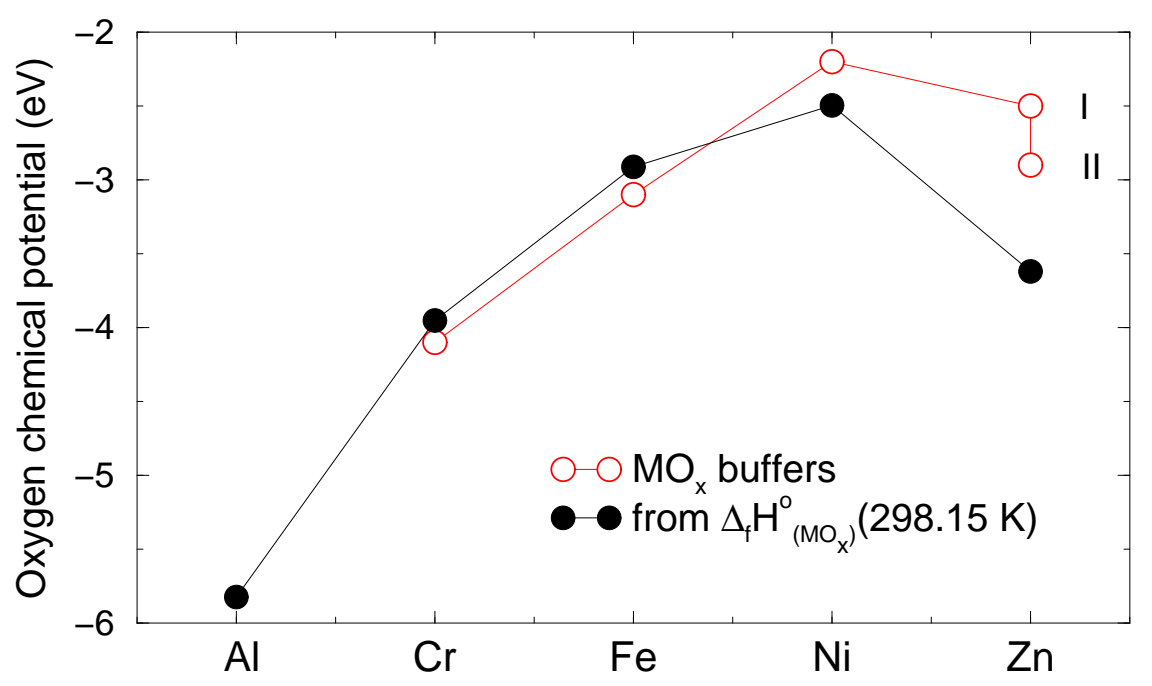

Figure 4: Critical values of oxygen chemical potential $\Delta \mu_{O}$ at which oxidation of the metallic buffers considered in this study is thermodynamically favored. Corresponding values deduced from the experimental standard enthalpies of oxide formation $\Delta_{f} H^{\circ}(298.15 K)$ (per oxygen atom) are given as a reference.

Taking into account the results reported in Sec. 3, it is clear that in extreme oxygenlean conditions in which the oxidation of metals from the middle of the transition series, such as Cr, can be avoided, the purely metallic buffers furnish the optimal performance. In oxygen-moderate conditions, the lower activity of late transition metals, such as $\mathrm{Ni}$, makes them better suited for a practical fabrication of purely metallic buffers. Indeed, due to weaker metal-oxygen bonds, the alumina/Ni interface is less adhesive compared to Cr, Tab. 2, but the Ni/Zn interaction is very satisfactory, and the overall performance of the alumina/nickel/zinc interface brings all the required improvements over the pure alumina/zinc case. Interestingly, let us note that in more oxygen-rich conditions, when buffer 
oxidation cannot be avoided, the oxidation-induced loss of adhesion at the two interfaces of the oxidized nickel buffer is much less dramatic compared to more reactive metals, Tab. 5, such that all considered $\mathrm{NiO}_{x}$ buffers are predicted to strengthen the pure alumina/zinc interface. However, the low activity of nickel towards oxygen may produce also an undesirable effect. As exemplified in Sec. 4, oxygen-rich $\mathrm{NiO}_{x}$ buffers $\left(\mathrm{Ni}-\mathrm{O}_{3}-\mathrm{Ni}\right.$ and $\left.\mathrm{O}-\mathrm{Ni}-\mathrm{O}\right)$, may result in a partial oxidation of zinc, which produces a decrease of adhesion within the zinc layer [(i $\left.i_{3}\right)$ interface, Tab. 5]. More generally, although less favored in a thin interfacial film than in bulk material (Fig. 4), zinc oxidation may be difficult to avoid and thus has to be taken into account upon devising an optimal buffer.

The above discussion shows that in oxygen-moderate conditions, no single metal or metal oxide buffer proves fully satisfactory. However, buffers composed of adequately chosen metal alloys may enable an efficient accommodation of an oxygen excess and the formation of strong metal-oxygen and metal-zinc bonds at the two interfaces. Alloying effects may also reduce the extent of undesirable zinc oxidation at the interface. Properties of such buffers will be the subject of a forthcoming study.

\section{Conclusions}

In summary, with the help of DFT calculations, we have investigated the impact of a buffer layer on the adhesion characteristics of the alumina/zinc interface, and have identified the key interface features responsible for its strength. By considering metallic buffers composed of transition metals from the middle and the end of the $3 d$ series we have evidenced trends in adhesion characteristics at both alumina/buffer and buffer/zinc interfaces and have linked them to the metal character. Moreover, considering a series of model oxide buffers, we have extended the analysis as to include the effect of buffer oxidation. The numerical calculations

have been systematically accompanied by an analysis of the number and type of interfacial bonds. It has enabled a well-founded rationalization of the calculated trends with arguments 
applicable to a wider range of similar systems.

Our results show that metallic buffers considerably enhance the adhesion of the weakly interacting alumina/zinc interface. The effect is particularly striking for metals from the middle of the transitions series, driven by strong interfacial metal-oxygen (M-O) and metalzinc (M-Zn) bonds. However, we have also shown that buffer oxidation tends to reduce the number of such strong bonds, and to reduce in most cases their favorable effect on adhesion. We argue that, since the oxidation of buffers composed of more reactive metals from the middle of the transition series may be difficult to avoid, the late transition elements, which produce good, albite not the best interfacial characteristics, may be more promising for applications.

Finally, since we have shown that oxidation of zinc has to be avoided, we suggest that adequately composed metal alloys may provide tunable oxidation characteristics which could enable the accommodation of an oxygen excess, the formation of strong metal-oxygen and metal-zinc bonds, with none or only limited zinc oxidation.

\section{Acknowledgments}

The authors are grateful to Jacques Jupille, Rémi Lazzari, Lucie Gaouyat and Daniel Chaleix for many fruitful discussions. They also acknowledge the financial support from ArcelorMittal Maizières Research, and a generous allocation of computing time at IDRIS, under Project No. 100170.

\section{References}

\section{References}

(1) Campbell, C. T. Ultrathin Metal Films and Particles on Oxide Surfaces: Structural, Electronic and Chemisorptive Properties. Surface Science Reports 1997, 27, 1-111. 
(2) Fu, Q.; Wagner, T. Interaction of Nanostructured Metal Overlayers with Oxide Surfaces. Surface Science Reports 2007, 62, 431-498.

(3) Bordier, G.; Noguera, C. Electronic Structure of a Metal-Insulator Interface: Towards a Theory of Nonreactive Adhesion. Phys. Rev. B 1991, 44, 6361-6371.

(4) Goniakowski, J.; Noguera, C. Electronic States and Schottky Barrier Height at Metal/MgO(100) Interfaces. Interf. Sci. 2004, 12, 93-103.

(5) Goniakowski, J.; Mottet, C.; Noguera, C. Non-reactive Metal/Oxide Interfaces: From Model Calculations Towards Realistic Simulations. phys. stat. sol. (b) 2006, 243, 25162532.

(6) Marder, A. R. The Metallurgy of Zinc-Coated Steel. Prog. Mater. Sci. 2000, 45, 191271.

(7) Beranger, G.; Henry, G.; (Eds.), G. S. The Book of Steel; Lavoisier Publishing: Intercept LTD, 1996; pp 1268-1278.

(8) Giorgi, M.-L.; Diawara, J.; Chen, S.; Koltsov, A.; Mataigne, J.-M. Influence of Annealing Treatment on Wetting of Steels by Zinc Alloys. J. Mater. Sci. 2012, 47, 8483-8495.

(9) Drillet, P.; Zermout, Z.; Bouleau, D.; Mataigne, J.-M.; Claessens, S. Selective Oxidation of High Si, Mn and Al Steel Grades During Recrystallization Annealing and Steel/Zn Reactivity. Rev. Metall.-Cah. Inf. Tech. 2004, 10, 831-837.

(10) Grässel, O.; Krüger, L.; Frommeyer, G.; Meyer, L. W. High Strength $\mathrm{Fe}-\mathrm{Mn}$ - (Al, Si) TRIP/TWIP Steels Development - Properties - Application. International Journal of Plasticity 2000, 16, 1391-1409.

(11) Jiang, H.-T.; Ding, W.; Tang, D.; Huang, W. Mechanical Property and Microstructural Characterization of $\mathrm{C}-\mathrm{Mn}-\mathrm{Al}-\mathrm{Si}$ Hot Dip Galvanizing TRIP Steel. J. Iron and Steel Research 2012, 19, 29-36. 
(12) Nikulin, I.; Sawaguchi, T.; Tsuzaki, K. Effect of Alloying Composition on Low-Cycle Fatigue Properties \& Microstructure of Fe $-30 \mathrm{Mn}-(6-\mathrm{x}) \mathrm{Si}-\mathrm{xAl}$ TRIP/TWIP Alloys. Materials Science and Engineering A 2013, 587, 192-200.

(13) Wang, W.; Li, M.; He, C.; Wei, X.; Wang, D.; Dub, H. Experimental Study on High Strain Rate Behavior of High Strength 600-1000 MPa Dual Phase Steels and 1200 MPa Fully Martensitic Steels. Materials and Design 2013, 47, 510-521.

(14) Mertens, A.; Bellhouse, E. M.; McDermid, J. R. Microstructure and Mechanical Properties of a Mixed Si - Al TRIP-Assisted Steel Subjected to Continuous Galvanizing Heat Treatments. Materials Science \& Engineering A 2014, 608, 249-257.

(15) Guttmann, M. Diffusive Phase Transformations in Hot Dip Galvanizing. Materials Science Forum 1994, 155-156, 527-548.

(16) Cavallotti, R. Effets de la Terminaison de l' $\alpha$-Alumine (0001) sur le Comportement au Mouillage du Zinc. Ph.D. thesis, Université Pierre et Marie Curie (UPMC), Paris, France, 2014.

(17) Goniakowski, J.; Fincocchi, F.; Noguera, C. Polarity of Oxide Surfaces and Nanostructures. Rep. Prog. Phys. 2008, 71, 016501-.

(18) Noguera, C.; Goniakowski, J. Polarity in Oxide Nano-objects. Chem. Rev. 2013, 113, 4073-4105.

(19) Causa, M.; Dovesi, R.; Pisani, C. Ab initio Characterization of the (0001) and (1010) Crystal Faces of $\alpha$-Alumina. Surf. Sci. 1989, 215, 259-271.

(20) Bogicevic, A.; Jennison, D. R. Variations in the Nature of Metal Adsorption on Ultrathin $\mathrm{Al}_{2} \mathrm{O}_{3}$ Films. Phys. Rev. Lett. 1999, 82, 4050-4053.

(21) Batyrev, I. G.; Alavi, A.; Finnis, M. W. Equilibrium and Adhesion of Nb/Sapphire: The Effect of Oxygen Partial Pressure. Phys. Rev. B 2000, 62, 4698-4706. 
(22) Li, H.; Zhang, W.; Smith, J. R. Advances in ab initio Thermodynamic Studies on Metal/Oxide Interfaces. Phys. Stat. Solidi A. 2011, 208, 1166-1173.

(23) Yoshitake, M.; Yagyu, S.; Chikyow, T. Novel Method for the Prediction of an Interface Bonding Species at Alumina/Metal Interfaces. J. Vac. Sci. Technol. A 2014, 32, $021102-1-8$.

(24) Lazzari, R.; Goniakowski, J.; Cabailh, G.; Cavallotti, R.; Trcera, N.; Lagarde, P.; Jupille, J. Surface and Epitaxial Stresses on Supported Metal Clusters. Nano Lett. 2016, 16, 2574-2579.

(25) Triboulet, R.; Perriere, J. Epitaxial Growth of ZnO Films. Progress in Crystal Growth and Characterization of Materials 2003, 47, 65-138.

(26) Rodriguez, J. A.; Kuhn, M.; Hrbek, J. Interaction of Silver, Cesium, and Zinc with Alumina Surfaces: Thermal Desorption and Photoemission Studies. J. Phys. Chem. 1996, 100, 18240-18248.

(27) Lazzari, R.; Jupille, J.; Cavallotti, R.; Simonsen, I. Model-free Unraveling of Supported Nanoparticles Plasmon Resonance Modes. J. Phys. Chem. C 2014, 118, 7032-7048.

(28) Cavallotti, R.; Goniakowski, J.; Lazzari, R.; Jupille, J.; Koltsov, A.; Loison, D. Role of Surface Hydroxyl Groups on Zinc Adsorption Characteristics on $\mathrm{Al}_{2} \mathrm{O}_{3}(0001)$ Surfaces: First-Principles Study. J. Phys. Chem. C 2014, 118, 13578-13589.

(29) Cavallotti, R.; Le, H.-L. T.; Goniakowski, J.; Lazzari, R.; Jupille, J.; Koltsov, A.; Loison, D. New Routes for Improving Adhesion at Metal $/ \mathrm{Al}_{2} \mathrm{O}_{3}(0001)$ Interface. Phys. Chem. Chem. Phys. 2016, 18, 3032-3039.

(30) Kresse, G.; Furthmuller, J. Efficient Iterative Schemes for ab initio Total Energy Calculations Using a Plane-Wave Basis Set. Phys. Rev. B 1996, 54, 11169-11186. 
(31) Kresse, G.; Hafner, J. Ab initio Molecular Dynamics for Liquid Metals. Phys. Rev. B $1993,47,558-561$.

(32) Blöchl, P. E. Projector Augmented-Wave Method. Phys. Rev. B 1994, 50, 17953-17979.

(33) Kresse, G.; Joubert, J. From Ultrasoft Pseudopotentials to the Projector AugmentedWave Method. Phys. Rev. B 1999, 59, 1758-1775.

(34) Dion, M.; Rydberg, H.; Schroder, E.; Langreth, D. C.; Lundqvist, B. I. Van der Waals Density Functional for General Geometries. Phys. Rev. Lett. 2004, 92, 246401-1-4.

(35) Klimes, J.; Bowler, D. R.; Michaelides, A. Chemical Accuracy for the van der Waals Density Functional. J. Phys.: Cond. Matt. 2010, 22, 022201-1-5.

(36) Klimes, J.; Bowler, D. R.; Michaelides, A. Van der Waals Density Functionals Applied to Solids. Phys. Rev. B 2011, 83, 195131-1-13.

(37) Kirfel, A.; Eichhorn, K. Accurate Structure Analysis with Synchrotron Radiation. The Electron Density in $\mathrm{Al}_{2} \mathrm{O}_{3}$ and $\mathrm{Cu}_{2} \mathrm{O}$. Acta Crystallographica A 1990, 46, 271-284.

(38) Wyckoff, R. W. G. Crystal Structures 1, Second edition.; Interscience Publishers: New York, 1963.

(39) Philipsen, P. H. T.; Baerends, E. J. Cohesive Energy of 3d Transition Metals: Density Functional Theory Atomic and Bulk Calculations. Phys. Rev. B 1996, 54, 5326-5333.

(40) Janthon, P.; Luo, S.; Kozlov, S. M.; nes, F. V.; Limtrakul, J.; Truhlar, D. G.; Illas, F. Bulk properties of Transition Metals: A Challenge for the Design of Universal Density Functionals. J. Chem. Theory Comput. 2014, 10, 3832-3839.

(41) Bader, R. F. W. A Quantum Theory of Molecular Structure and its Applications. Chem. Rev. 1991, 91, 893-928. 
(42) Henkelman, G.; Arnaldsson, A.; Jonsson, H. A Fast and Robust Algorithm for Bader Decomposition of Charge Density. Comput. Mater. Sci. 2006, 36, 354-360.

(43) Melnikov, V. V.; Yeremeev, S. V.; Kulkova, S. E. Theoretical Investigation of 3d-Metal Adsorption on the $\alpha-\mathrm{Al}_{2} \mathrm{O}_{3}(0001)$ Surface. Russ. Phys. J. 2011, 54, 704-712.

(44) Goniakowski, J. Transition Metals on the MgO(100) Surface: Evolution of Adsorption Characteristics Along the 4d Series. Phys. Rev. B 1999, 59, 11047-11052.

(45) Goniakowski, J.; Noguera, C. Microscopic Mechanisms of Stabilization of Polar Oxide Surfaces: Transition Metals on the $\mathrm{MgO}(111)$ Surface. Phys. Rev. B 2002, 66, 0854171-9.

(46) Goniakowski, J.; Noguera, C. Polarization and Rumpling in Oxide Monolayers Deposited on Metallic Substrates. Phys. Rev. B 2009, 79, 155433-1-5.

(47) Goniakowski, J.; Noguera, C.; Giordano, L.; Pacchioni, G. Adsorption of Metal Adatoms on $\mathrm{FeO}(111)$ and $\mathrm{MgO}(111)$ Monolayers: Effects of Charge State of Adsorbate on Rumpling of Supported Oxide Film. Phys. Rev. B 2009, 80, 125403-1-7.

(48) Chase, M. W. NIST - JANAF Thermochemical Tables, 2 Volume-Set (J. Phys. Chem. Ref. Data Monographs); American Institute of Physics, 1998; Vol. 4th Edition, Monograph 9.

(49) Cox, J. D.; Wagman, D. D.; Medvedev, V. A. CODATA Key Values for Thermodynamics; Hemisphere Publishing Corp.: New York, 1984. 